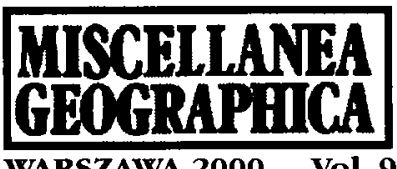

WARSZAWA 2000 Vol. 9

Krzysztof Olszewski

\title{
DEPENDENCE OF ACIDITY OF PRECIPITATION UPON ATMOSPHERIC CIRCULATION
}

There is a disadvantageous atmospheric phenomenon, which has appeared during the last several decades, constituted by acid rain. The primary cause of its appearance is the emission of the sulphur and nitrogen compounds to the atmosphere. Research demonstrated that 2-4 hours after emission of these gases only $30 \%$ of the emitted volume settles on the Earth's surface, while the rest is transported away from the area of emission and takes part in the so called wet deposition, entering into chemical reactions with water vapour and water contained in the atmosphere (Mészáros, 1981). It is considered that the limit of the chemically "normal" precipitation is $\mathrm{pH}=5.6$. Lower values of $\mathrm{pH}$ indicate acid precipitation.

The natural source of acidifying gases include volcanic eruptions, sea aerosols, as well as decaying plants and sea plankton. Humans supply the atmosphere with these gases primarily by burning fossil fuels.

Acid precipitation causes significant damages in the environment, not only in the areas featuring high concentrations of sulphur and nitrogen compounds. Atmospheric circulation transports these compounds over often important distances from the emission sources and they fall down there in the form of acid precipitation, acidifying the soils and waters, and destroying organic life, structures, etc. Thus, it is not just a local problem of a given country. Currently in Poland, similarly as in the whole of Central Europe, the $\mathrm{pH}$ of precipitation oscillates around 4.5 , meaning that this precipitation is at least ten times more acid than the normal rain (L'évaluation de la pollution..., 1991).

In order to inquire into the role played by the atmospheric circulation in formation of acid rain a weather station was selected in one of the least polluted areas in Poland, Diabla Góra, located in Borecka Forest ( $\phi=54^{\circ} 09^{\prime}$; $\lambda=22^{\circ} 04^{\prime}$ ). This station is an element in the international EMEP network, and the measurements made there can be considered representative for the area of Central and Eastern Europe. The data concerning the acidity of the precipitation have been gathered in the years 1993-1998 and were made available by the Environmental Protection Institute. The types of atmospheric circulation for the same period were taken from Lityński (1969). 
ANNUAL CHANGES OF THE pH VALUE OF PRECIPITATION

In the period considered the average acidity of precipitation was $\mathrm{pH}=$ 4.8, meaning that it was on the whole acidic, with actual values ranging between $\mathrm{pH}=3.3$ (May $16^{\text {th }}, 1995$ ) and $\mathrm{pH}=7.5$ (August $3^{\text {rd }}, 1998$ ). Annual cycle is well clearly pronounced (see Fig. 1), with the lowest values of $\mathrm{pH}$ in the cooler half of the year, and the highest ones - in the warmer half. Connection with the emissions of sulphur dioxide appears obvious. Emissions, namely, increase in the heating season. That is why the monthly values of $\mathrm{pH}$ are the lowest between December and March (Fig. 2) and do not exceed 4.5. The least acidified precipitation is observed between June and September, when the average value of $\mathrm{pH}$ does not fall below 5.0, though it still does not attain the limit denoting the neutral precipitation $(\mathrm{pH}=5.6)$. Thus, over the whole year the average value of $\mathrm{pH}$ indicates an acidic precipitation. During the year such a precipitation is observed in $84 \%$ of days with precipitation. Most often (more than $60 \%$ of days with precipitation) the acidity ranged between 4.1 and 5.0 (Fig. 3). Only in $16 \%$ of days precipitation was not acidic.

As mentioned, one of the causes of acid rains is pollution transport, which is brought about by atmospheric circulation. Hence, dependence of the acidity of precipitation on the circulation type was analysed. It was considered in two aspects - direction of circulation and pressure configuration.

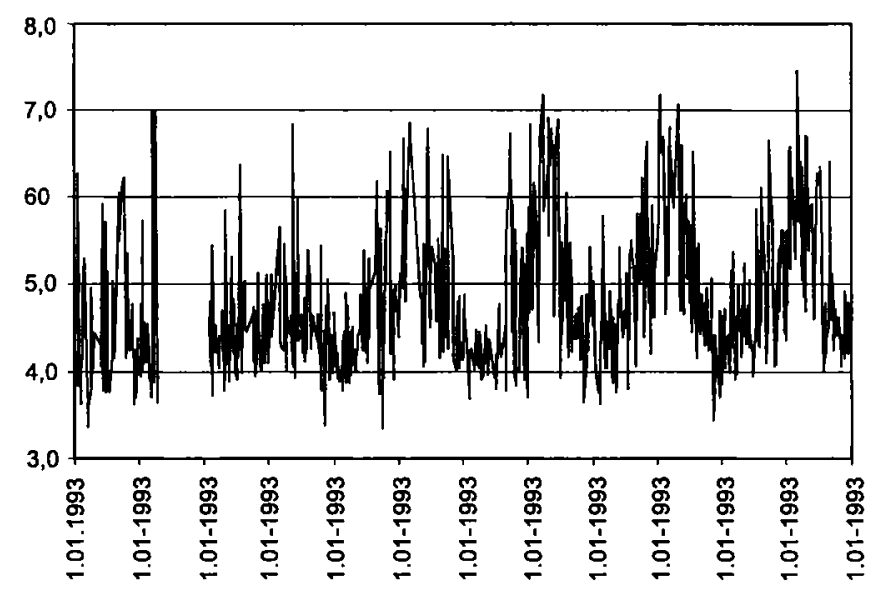

Fig. 1. Daily changes of pH measurements of precipitation. Diabla Góra, 1993-1998.

\section{ACIDITY OF PRECIPITATION AND THE DIRECTION OF CIRCULATION}

The analysis of the average values of $\mathrm{pH}$ as a function of the direction of circulation indicated that acid precipitation are brought to north-eastern Poland from all directions. The average value of $\mathrm{pH}$ for each of the circulation 


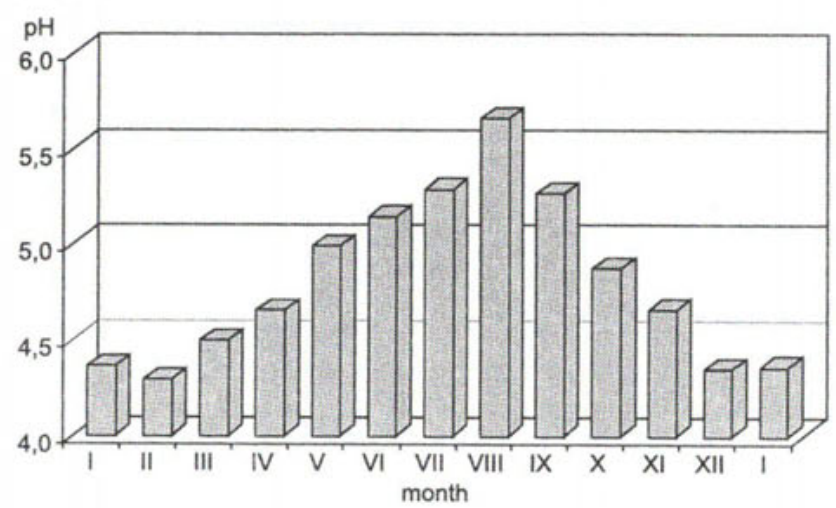

Fig. 2. Annual changes of pH measurements of precipitation. Diabla Góra, 1993-1998.

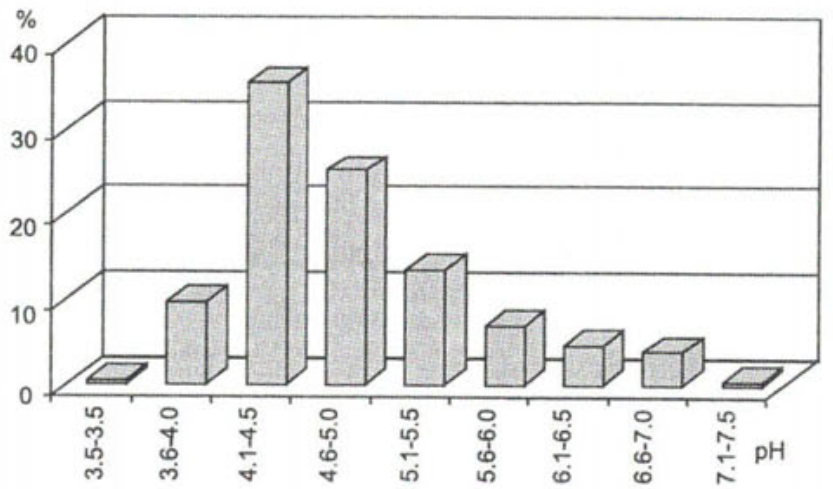

Fig. 3. Frequency (in \%) of appearance of particular values of $\mathrm{pH}$ measurements. Diabla Góra, 1993-1998.

directions is lower than 5.6 (Fig. 4). It can be noticed that the most acidic precipitation $(\mathrm{pH}<5.0)$ flows in from the western sector (from $\mathrm{S}$ through $\mathrm{W}$ up to $\mathrm{N}$ ). Circulation from the eastern sector (between $\mathrm{NE}$ and SE) brings less acidic precipitation $(5.0<\mathrm{pH}$ $<5.6$ ), though $\mathrm{pH}$ is still below the neutrality threshold. The inflow of acidic precipitation from the western sector corresponds to the distribution of sulphur dioxide pollution in Poland and in Europe. The frequency of inflow of acidic precipitation was the highest in this period. These directions of circulation occurred in more than $75 \%$ of days.

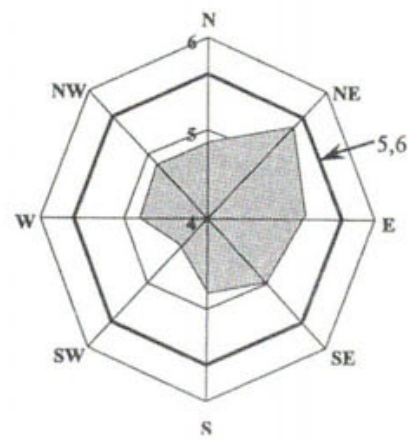

Fig. 4. Average values of $\mathrm{pH}$ for particular directions of circulation. Diabla Góra, 1993-1998.

The analysis of frequency of appearance of particular values of $\mathrm{pH}$ as depending upon the direction of circulation confirms our previous observa- 

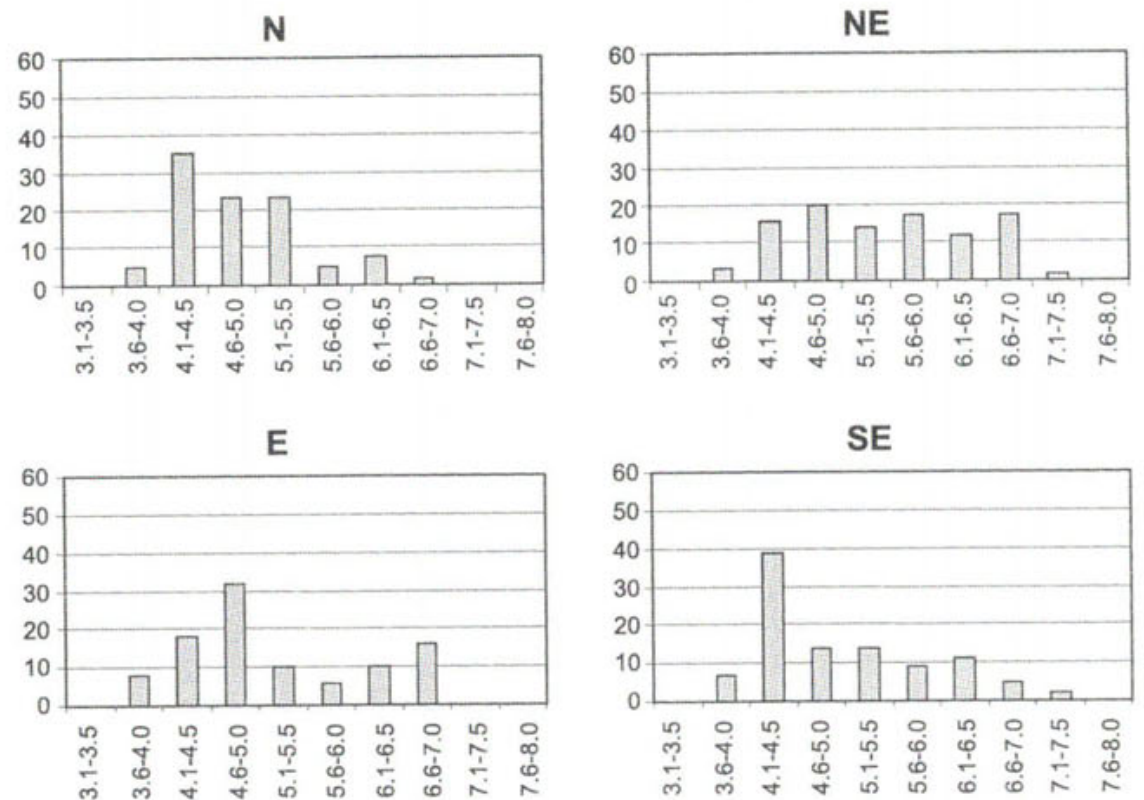

S

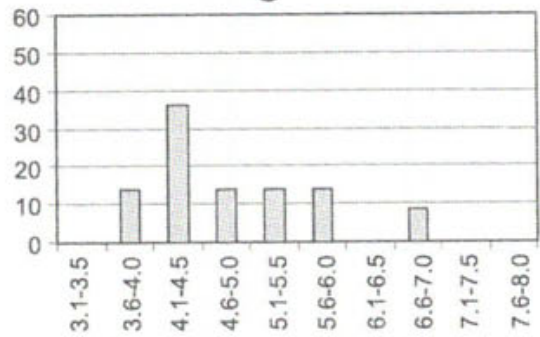

SW

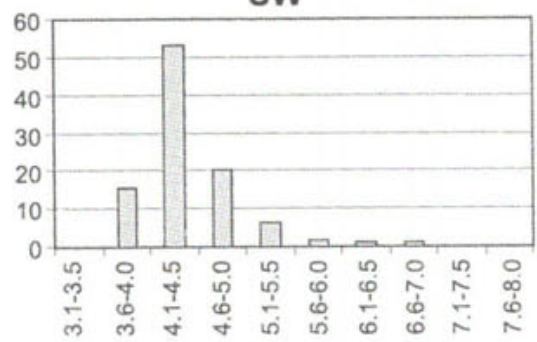

W
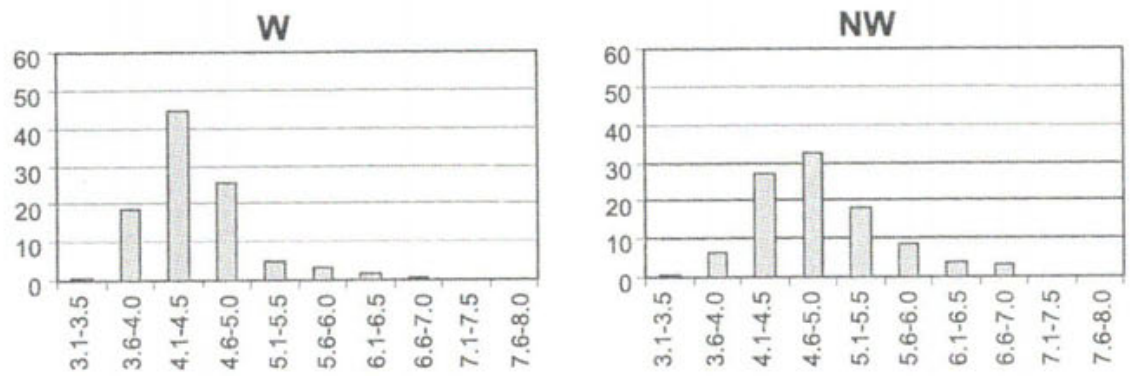

Fig. 5. Frequency (in \%) of appearance of definite $\mathrm{pH}$ values for particular circulation directions. Diabla Góra, 1993-1998.

tions (see Fig. 5). The most acidic precipitation is brought from the western sector - its $\mathrm{pH}$ most often ranged from 4.1 to 4.5 . It is from the western direction that the precipitation with the lowest $\mathrm{pH}$ value, $\mathrm{pH}=3.3$, was 
brought. The neutral precipitation ( $\mathrm{pH}$ close to 5.6 ) is marginal. The most often observed $\mathrm{pH}$ values fall in the interval 4.6-5.0.

\section{THE ACIDITY OF PRECIPITATION AND THE ATMOSPHERIC PRESSURE CONFIGURATIONS}

The type of pressure configuration does not differentiate the values of $\mathrm{pH}$ like the direction of circulation does. Both in the cyclone and anticyclone configurations the average value of $\mathrm{pH}$ was 4.8 , meaning acidic precipitation. Likewise, in both types of circulation precipitation of $\mathrm{pH}$ between 4.1 and 5.0 (see Fig. 6) appeared most often. It can be observed, though, that precipitation featuring very high acidity $(\mathrm{pH}<4.0)$ occurs more often during the anticyclone configurations than during the cyclone ones.
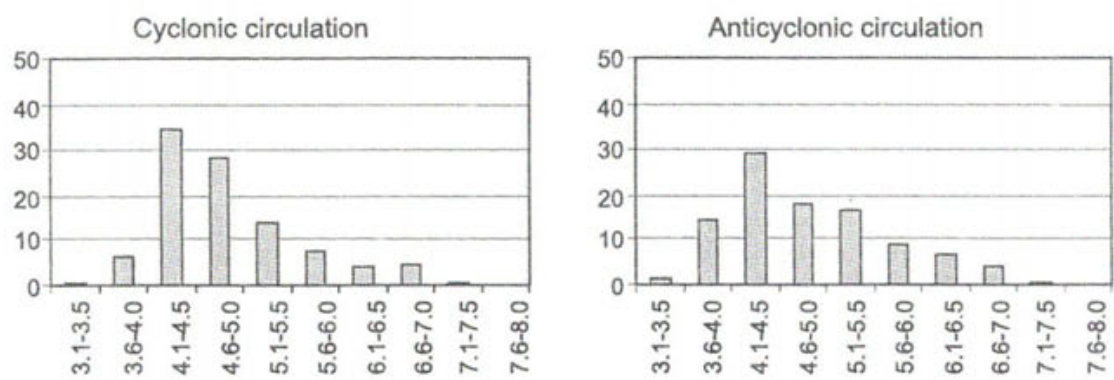

Fig. 6. Frequency (in \%) of appearance of definite $\mathrm{pH}$ values for particular configurations of atmospheric pressure. Diabla Góra, 1993-1998.

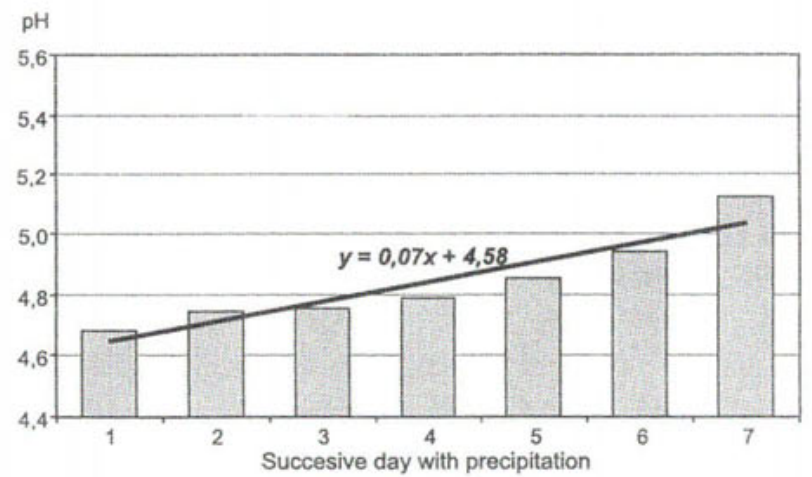

Fig. 7. Changes in the $\mathrm{pH}$ values in consecutive days with precipitation. Diabla Góra, 1993-1998.

The acidity of water in precipitation decreases along with the length of the time period with precipitation. The longer the period during which precipitation occurs every day, the lower the value of $\mathrm{pH}$. In the period analysed 
several dozens of periods of a couple of days of length, such that precipitation occurred every day (Fig. 7) could be determined. Owing to washing away of pollution from the air the acidity of precipitation decreased. It was calculated that within the seven-day every-day-rain periods distinguished in the analysis the average value of $\mathrm{pH}$ increased from 4.7 on the first day to 5.1 on the last one.

\section{REFERENCES}

L'évaluation de la pollution atmosphérique transfrontière à longue distance, 1991, Nations Unies, New York.

Lityński J., 1969, Liczbowa klasyfikacja typów cyrkulacji i typów pogody dla Polski

[Numerical classification of circulation and weather types for Poland], Prace PIHM, issue 97 , Warszawa.

Més zár os E., 1981, Atmospheric Chemistry, Akadémiai Kiado, Budapest.

Pawlick T., 1984, A Killing Rain - the Global Threat of Acid Precipitation, Douglas \& McIntyre, Vancouver-Toronto. 